\title{
Oxytocin nasal spray in fibromyalgic patients: additional information
}

\author{
Reply to the comment to the editor entitled "Future directions for the investigation \\ of intranasal oxytocin and pain"
}

\author{
Roberta Agabio • Sergio Mameli • Salvatore Sardo • \\ Luigi Minerba $\cdot$ Maria Rosaria Melis
}

Received: 1 July 2014 / Accepted: 17 July 2014

(C) Springer-Verlag Berlin Heidelberg 2014

We read with interest the Letter of Drs. Rash and Campbell [1] and are grateful to them for the opportunity to provide additional information to our short communication [2].

Regarding the procedure of the administration, the recommendations suggested by Guastella and colleagues were adopted [3]. During the first week, the dose was equal to 5 puffs (20-IU) twice a day, then, to 10 puffs (40-IU) twice a day. The composition of the oxytocin and placebo nasal sprays was identical, except for the hormone. It is difficult to determine what influence the expectation of effects had on our results, as no data were collected on expectations. However, the lack of differences between the groups suggests that oxytocin did not enhance placebo analgesia in our experimental conditions.

Our study was aimed at investigating the possible effectiveness of chronic treatment in reducing the severity of pain. Accordingly, medications were self-administered by participants, twice daily, with a 12-h interval, for 3 weeks. Patients registered the severity of pain at the end of the day, regardless of the time of the administration. At each weekly visit, the experimenter registered the severity of pain, regardless of the time of administration.

This reply refers to the article available at doi:10.1007/s00296-014-3070-7.

R. Agabio $(\varangle) \cdot$ M. R. Melis

Section of Neuroscience and Clinical Pharmacology, Department of Biomedical Sciences, University of Cagliari, Cagliari, Italy

e-mail:agabio@unica.it

S. Mameli $\cdot$ S. Sardo

Pain Therapy Unit, “A. Businco” Hospital, ASL 8, Cagliari, Italy

L. Minerba

Department of Public Health, Clinical Medicine and Molecular,

University of Cagliari, Cagliari, Italy
A possible acute, analgesic effect of oxytocin was investigated at the beginning of the study. After baseline evaluation, patients self-administered oxytocin (20-IU) or placebo and waited for $1 \mathrm{~h}$, when central oxytocin levels achieve the highest values [4-6]. Then, the severity of actual pain was investigated, but no difference was found (placebo $43.3 \pm 10.6$; oxytocin $47.2 \pm 16.2, p=0.15, t$ test). The acute effects of $40-\mathrm{IU}$ was not examined as patients started with this dose after 1 week of a $20-\mathrm{IU}$ treatment, and this evaluation would not be a reliable measure of 40-IU acute effects.

Under our experimental conditions, chronic treatments with 20-IU or 40-IU did not reduce the severity of pain. We concluded that higher doses or long periods of treatment might unravel an analgesic effect of oxytocin. Recent studies found that 24-IU of oxytocin (1) induced stronger effects than 48-IU in cortisol response to intense exercise [7] and (2) was effective in reducing obesity if administered 4 times daily for 8 weeks [8]. Accordingly, the ideal schedule seems to be constituted by more frequent daily administrations of lower doses, and for longer periods of time than those used in our studies (e.g., 24-IU, 4 times daily for at least 8 weeks rather than 40-IU twice daily for 3 weeks).

Despite the large body of preclinical evidence suggesting an analgesic effect of oxytocin, the number of clinical studies is scarce. A recent review [9] reported that only five studies investigated this effect: among these, three studies found positive effects [10-12], one promising results [13], and one inconclusive results [14]. Recently, two additional clinical studies found opposite results $[2,15]$. The difference between results may be due, at least in part, to the different patient samples (fibromyalgic patients vs. healthy adults) and methodological procedures (chronic vs. acute treatment; chronic unresponsive vs. acute cold pressor pain). 
Although the number of patients would have needed to be higher to detect small effects of oxytocin, this number was justified by the need to investigate whether oxytocin was safe in these patients, also affected by mental comorbidity and undergoing a complex pharmacotherapy. Our aims comprised not only the effectiveness but also the safety of oxytocin.

Further clinical studies are needed to improve our knowledge on the analgesic effects of oxytocin using different typologies of participants (health adults and patients with acute or chronic pain), methodological procedures (spontaneous and induced pain), and treatments (acute and chronic treatment; lower and higher doses; number of daily administrations).

\section{References}

1. Rash JA, Campbell TS (2014) Future directions for the investigation of intranasal oxytocin and pain: Comment on: Oxytocin nasal spray in fibromyalgic patients (Rheumatol Int. E-pub ahead of print. doi: 10.1007/s00296-014-2953-y). Rheumatol Int 34:1177-1178

2. Mameli S, Pisanu GM, Sardo S, Marchi A, Pili A, Carboni M, Minerba L, Trincas G, Carta MG, Melis MR, Agabio R (2014) Oxytocin nasal spray in fibromyalgic patients. Rheumatol Int 34:1047-1052

3. Guastella AJ, Hickie IB, McGuinness MM, Otis M, Woods EA, Hannah M et al (2013) Recommendations for the standardization of oxytocin nasal administration and guidelines for its reporting in human research. Psychoneuroendocrinology 38:612-625

4. Huffmeijer R, Alink LR, Tops M, Grewen KM, Light KC, Bakermans-Kranenburg MJ, Ijzendoorn MH (2012) Salivary levels of oxytocin remain elevated for more than two hours after intranasal oxytocin administration. Neuro Endocrinol Lett 33(1):21-25
5. Striepens N, Kendrick KM, Hanking V, Landgraf R, Wüllner U, Maier W et al (2013) Elevated cerebrospinal fluid and blood concentrations of oxytocin following its intranasal administration in humans. Sci Rep 3:3440

6. van Ijzendoorn MH, Bhandari R, van der Veen R, Grewen KM, Bakermans-Kranenburg MJ (2012) Elevated salivary levels of oxytocin persist more than $7 \mathrm{~h}$ after intranasal administration. Front Neurosci 6:174

7. Cardoso C, Ellenbogen MA, Orlando MA, Bacon SL, Joober R (2013) Intranasal oxytocin attenuates the cortisol response to physical stress: a dose-response study. Psychoneuroendocrinology 38:399-407

8. Zhang H, Wu C, Chen Q, Chen X, Xu Z, Wu J et al (2013) Treatment of obesity and diabetes using oxytocin or analogs in patients and mouse models. PLoS ONE 8:e61477

9. Rash JA, Aguirre-Camacho A, Campbell TS (2014) Oxytocin and pain: a systematic review and synthesis of findings. Clin J Pain 30:453-462

10. Louvel D, Delvaux M, Felez A, Fioramonti J, Bueno L, Lazorthes $Y$ et al (1996) Oxytocin increases thresholds of colonic visceral perception in patients with irritable bowel syndrome. Gut 39:741-747

11. Uryvaev Iu V, Petrov GA (1996) Decreased pain sensitivity in man after treatment with superlow doses of oxytocin. Biull Eksp Biol Med 122:487-489

12. Yang J (1994) Intratecal administration of oxytocin induces analgesia in low back pain involving the endogenous opiate peptide system. Spine 19:867-871

13. Ohlsson B, Truedsson M, Bengtsson M, Torstenson R, Sjölund $\mathrm{K}$, Björnsson ES et al (2005) Effects of long-term treatment with oxytocin in chronic constipation; a double blind, placebo-controlled pilot trial. Neurogastroenterol Motil 17:697-704

14. Singer T, Snozzi R, Bird G, Petrovic P, Silani G, Heinrichs M et al (2008) Effects of oxytocin and prosocial behavior on brain responses to direct and vicariously experienced pain. Emotion 8:781-791

15. Rash JA, Campbell TS (2014) The effect of intranasal oxytocin administration on acute cold pressor pain: a placebo-controlled, double-blind, within-subjects crossover investigation. Psychosom Med 76:422-429 